\title{
Topical treatment of experimental cutaneous leishmaniasis in golden hamster (Mesocricetus auratus) with formulations containing pentamidine
}

\author{
Claudia Dantas COMANDOLLI-WYREPKOWSKI ${ }^{*}$, Iryna GRAFOVA², Maricleide de Farias NAIFF ${ }^{1}$, \\ Maurizio AVELLA ${ }^{3}$, Gennaro GENTILE ${ }^{3}$, Andriy GRAFOV ${ }^{2}$, Antonia Maria Ramos FRANCO ${ }^{1}$ \\ 1 Instituto Nacional de Pesquisas da Amazônia (INPA). Laboratory of Leishmaniasis and Chagas Disease. Av. André Araújo, 2936, Petrópolis.CEP 69067-375, Manaus-AM. Brazil; \\ 2 University of Helsinki, Laboratory of Inorganic Chemistry, Chemistry Institute. A.I .Virtasenaukio 1, 00014, Helsinki, Finland. \\ ${ }^{3}$ Istituto di Chimica e Tecnologia dei Polimeri (ICTP)- Consiglio Nazionale delle Ricerche (CNR), Via Campi Flegrei, 34, 80078, Pozzuoli, Napoli, Italy. \\ *Corresponding author: klaudiadcw@gmail.com
}

\section{ABSTRACT}

Current treatment of cutaneous leishmaniasis (CL) relies mainly on pentavalent antimonials salts and second-line drugs include pentamidine and amphotericin B, but these therapies have side effects and require parenteral administration. The aim of this work was to evaluate the topical formulations containing pentamidine isethionate (PI) in the experimental treatment of cutaneous leishmaniasis (CL). Golden hamsters (Mesocricetus auratus) were infected in the nose with Leishmania (Leishmania) amazonensis. Six treatment groups received different topical treatments of anhydrous or hydrating emulsions, for a maximum of 10 days, with an application of $50 \mathrm{mg} \mathrm{day}^{-1}$. After treatment tissue samples of lesions were evaluated by histology, transmission electron microscopy and biopsy cultivation. Compared with untreated group, topical treatment with hydrating emulsion with $10 \% \mathrm{PI}$ and usnic acid (ACE5AU) showed significantly decrease in volume lesion ( $\mathrm{P}=0.028)$ on $20^{\text {th }}$ day after the end of the treatment with reduction of $27.37 \%$. Topical treatment with anhydrous emulsion with $10 \%$ PI and usnic acid (ACPU) reduces parasite burden in Golden hamsters. This study demonstrated the potential of topical treatment to reduce the number of parasites that could be combined with others drugs and to have a faster and more effective treatment of cutaneous leishmaniasis.

KEYWORDS: topical formulations, experimental treatment, pentamidine isethionate, animal model, Leishmania

\section{Tratamento tópico da leishmaniose cutânea experimental em golden hamsters (Mesocricetus auratus) com fórmulas contendo pentamidina}

\begin{abstract}
RESUMO
O tratamento atual para Leishmaniose Tegumentar Americana é realizado com antimoniais pentavalentes como tratamento padrão, e as drogas de segunda escolha incluem pentamidina e anfotericina B, mas essas terapias apresentam efeitos colaterais e requerem administração parenteral. $\mathrm{O}$ objetivo deste trabalho foi avaliar formulaçóes tópicas contendo isetionato de pentamidina comercial (IP) no tratamento da leishmaniose cutânea experimental (LC). Hamsters dourados foram infectados no focinho com Leishmania (Leishmania) amazonensis. Grupos de seis animais receberam tratamento tópico com cremes anidro ou emulsóes hidratantes, num máximo de 10 dias, com aplicação de $50 \mathrm{mg} \mathrm{dia}^{-1}$. Amostras de tecido de lesôes tratadas foram avaliadas por histologia, microscopia eletrônica de transmissão (MET) e cultivo de biópsia. Comparado ao grupo sem tratamento, o tratamento tópico com emulsão hidratante com 10\% de IP e ácido úsnico (ACE5AU) mostrou diminuição significativa $(\mathrm{P}=0,028)$ nas medidas de lesóes, 20 dias após o final do tratamento e 27,37\% de redução. $\mathrm{O}$ tratamento tópico com emulsão anidra com 10\% de IP e ácido úsnico (ACPU) mostrou redução da carga parasitária em Golden hamsters. Este estudo demonstrou a possibilidade de utilizar o tratamento tópico para reduzir o número de parasitas e que este poderia ser associado a outras drogas para tratamento mais rápido e eficaz da leishmaniose cutânea.
\end{abstract}

PALAVRAS-CHAVE: formulaçóes tópicas, isetionato de pentamidina, tratamento experimental, modelo animal, Leishmania 


\section{INTRODUCTION}

Leishmaniasis is a chronic inflammatory infectious and parasitic disease caused by obligatory intracellular parasites of the genus Leishmania (Murray et al. 2005) that affect different types of tissue depending on the species involved (Guizani et al. 2011). Leishmaniasis is a public health issue in 98 countries, and there is an annual occurrence of two million new cases reported each year. In addition, more than 15 million people are infected Worldwide in a risk area that encompasses more than 350 million people (Alvar et al. 2012). Reports of epidemics have occurred in the Northeast of Brazil and Amazon region related to predatory colonization processes (Pinheiro et al. 2008). Leishmania is transmitted by insect vector, Phlebotomus species in the Old World and Lutzomyia species in the New World (Bates 2007). Treatment of leishmaniasis is still very limited and depends on the clinical way the disease manifests (cutaneous or visceral). The pentavalent antimonial salt such as $\mathrm{N}$-methylglucamine antimonate (Glucantime ${ }^{\circledast}$ ) and sodium stibogluconate (Pentostam ${ }^{\oplus}$ ) remain the first-line drugs for the treatment of leishmaniasis for over 50 years (Almeida and Santos 2011), but they are strongly associated with numerous side effects. In addition to antimony, other drugs have been used in the treatment of various forms of leishmaniasis, among which we highlight: Pentamidine, Amphotericin B, miltefosine and paromomycin (Rath et al. 2003). However, each of these therapies has serious limitations, including long-term parenteral administration, toxic side effects, high cost in endemic countries, and a large number of cases of resistance, predominantly associated with co-infection with the human immunodeficiency virus (HIV) [Croft et al. 2006]. Pentamidines are aromatic diamidines that have been used as second-line drugs in the treatment of Leishmaniasis in endemic areas (Singh et al. 2012) and commercialized for use in humans in the following formulations: isethionate (Di-hydroxyethane-sulfonate B) and mesylate (B-DiHydroxymethyl-sulfonate) [Alvar et al. 2006]. The discovery of the antiprotozoal activity of diamidines has led to the demand for hypoglycemic compounds that could compromise energy metabolism of parasites (Croft et al. 2006). Pioneering studies with topical formulations [Topical treatment (TT)] to the treatment of leishmaniasis were performed by El-On et al. (1986), using preparations of antibiotics of the aminoglycoside class, paromomycin, using 15\% paromomycin sulphate and $12 \%$ methyl benzethonium chloride in a hydrophobic base treatment of cutaneous leishmaniasis (CL) caused by Leishmania (Leishmania) major. The development of topical formulations could be an alternative method for the treatment of CL. Although the transdermal transport of drugs has many advantages over other routes of administration, there are still problems that need to be investigated, such as low penetration of most compounds through the human skin (Rossi-Bergmann et al. 2011). The aim of this study was to investigate the effects of topical treatment with formulations containing pentamidine isethionate/PI (Pentacarinat ${ }^{\odot / S a n o f i) ~ i n ~ e x p e r i m e n t a l l y ~}$ induced leishmanasis in Golden hamsters (Mesocricetus auratus) infected with Leishmania (Leishmania) amazonensis.

\section{MATERIALS AND METHODS}

Origin and maintenance of parasites: The strain MHO/BR/2006/IM5584 of L. (L.) amazonensis, was characterized, cryopreserved and kept in the Laboratory of Leishmaniasis and Chagas's Disease, Research Coordination of Environment, Society and Health, National Institute of Amazonian Research - INPA, Amazonas, Brazil. The parasites were grown in a biphasic medium NNN, and the culture was expanded in complete RPMI medium 1640 (Himedia), supplemented with $10 \%$ inactivated fetal calf serum (iFCS), gentamycin $\left(40 \mu \mathrm{g} \mathrm{mL} \mathrm{mL}^{-1}\right)$ and cryopreserved in liquid nitrogen.

Production of the formulations: Six different topical formulations were prepared using Polawax ${ }^{\oplus}$ as emulgent and $30 \%$ of commercial vegetable oils Andiroba (A) and Copaiba (C) for hydrating creams and 50\% of oils for anhydrous creams. Methylparaben and propylparaben were both used as preservatives. All formulations are non-ionic emulsion creams produced by the phase inversion method. Hydrating creams were: ACE0B (containing only oils, emulgent and preservatives) ACE5A (10\% PI [pentamidine isethionate (Pentacarinat ${ }^{\oplus / S a n o f i]}$ ) and ACE5AU (10\% PI and 10\% of usnic acid), and the anhydrous emulsions were: ACP $(10 \%$ of PI), ACPU (10\% of PI and $10 \%$ of usnic acid) and ACU (10\% of usnic acid).

Origin and infection of animals: Experimental animals used were 60 golden hamsters, all adult males from the Central Animal Laboratory of INPA, kept in cages in rooms conditioned with photoperiod, temperature constant, feeding conditions ad libitum and pathogens free (Project approved by Ethic Committee in Animal Research of the National Institute for Amazonian Research / INPA-CEUA, registration/approval number 009/2012).

Experimental design: The animals were separated into experimental groups, in nose of each one was inoculated with $0.01 \mathrm{~mL}$ of $L$. (L.) amazonensis promastigotes $\left(10^{6}\right.$ cells. $\left.\mathrm{mL}^{-1}\right)$. The animals remained under supervision for 21 days until the appearance of lesions. After the lesions established, they were measured to ensure homoscedasticity of treatment groups for the total volume of the lesion. The animals were used in two separate experiments: I - a total of 36 hamsters were infected and separated into three separate groups for topical treatments with hydrating creams ACE5A, ACE5AU, $\mathrm{ACE} 0 \mathrm{~B}$ and a control group without treatment (negative control/NC). The treatment groups received an emulsion 
applied to the lesion, $50 \mathrm{mg} \mathrm{day}^{-1}$, for eight consecutive days. The animals remained under observation with data collection for over 32 days without treatment. The test subjects for this experiment were euthanized 40 days after the trial; II - 24 hamsters infected, separated in groups for topical treatments with anhydrous creams ACP, ACPU, ACU, and a control group that did not receive a treatment (NC). The treatment groups received an emulsion at the lesion site with $50 \mathrm{mg}$ day $^{-1}$, for 10 consecutive days and the animals were kept under observation for 20 days. The test subjects for this experiment were euthanized 30 days after the trial.

Evaluation of treatment effects: Clinical evaluation: Each animal was subjected to daily evaluation to determine the amounts of the total lesion volume (length, width and height) using pachymeter (Zaas Precision ${ }^{\circ}$ ) to analyze the progression of the lesion. The numerical data were then recorded, tabulated and analyzed statistically. Lesions were also photo documented for the analysis of morphological evolution. Euthanasia: The animals were euthanized with Euthanyle $^{\bullet}$ (sodium pentobarbital - phenytoin sodium) in accordance with the INPA's commission on the ethical treatment of animals. Parasitological studies: A tissue sample sectioned from the lesion area of each animal was used for an imprint on glass slides. The slides were stained with Giemsa (Sigma), and the infectivity index was determined by multiplying the percentage of macrophages that had at least one intracellular parasite by the average number of intracellular parasites per infected macrophage (at least 200 cells were examined/animal). Viability of parasites in culture medium: Tissue fragments of lesions were cultivated in NNN medium for eight days at $25^{\circ} \mathrm{C}$ to observe the parasite viability. Tissue samples were sectioned from each area of the animal lesion. The dimensions of $1.0 \times 1.0 \times 1.0 \mathrm{~mm}$ were fixed in glutaraldehyde in $0.1 \mathrm{M}$ of cacodylate buffer $(2.5 \%$ $\mathrm{v} / \mathrm{v}$ ) and underwent analysis by Transmission Electronic Microscoscopy (TEM). Blocks were prepared with an Epoxy - Embedding Kit (Sigma-aldrich ${ }^{\circ}$ ), and the experiments were performed on a FEI TECNAI G12 Spirit-Twin (120 $\mathrm{kV}$, LaB6) microscope equipped with a FEI Eagle 4k CCD camera (Eindhoven, The Netherlands). Prior to observations, thin sections of the samples (nominal thickness $100 \mathrm{~nm}$ ) were obtained by a Leica UC7 ultramicrotome (Wien, Austria) and placed on 400 mesh copper grids. Statistical analysis: It was performed using the GraphPad Prism software (version 6.0 for Windows). A one-way ANOVA statistical test was used to assess the significance of the differences between the various groups followed by Tukey's test to compare the means of different treatment groups, with $95 \%$ confidence to be considered significant.

\section{RESULTS}

Evaluation of lesion size is an important parameter, mainly in the species that we can observe with nodular lesions with the presence of histiocytomas. Nodular lesions caused by L. (L.) amazonensis developed 21 days after inoculation, followed by ulceration in 63 days post infection.

The topical treatment (TT) was initiated 21 days post infection. Figure 1 shows the results of the evolution of the lesion volume in relation to the days of application and observation after the end of the treatment with hydrating creams and anhydrous creams. The average size of the lesions remained under steady growth in 30 to 40 days after initiation of treatment and progression to ulcerated lesions may be observed in certain animals.

Among the hydrating creams, ACE5AU formulation demonstrated effectiveness in the clinical aspect and efficiency by reducing the total volume of lesions, compared with the average of the control group (Figure 1-A). The ACE0B cream

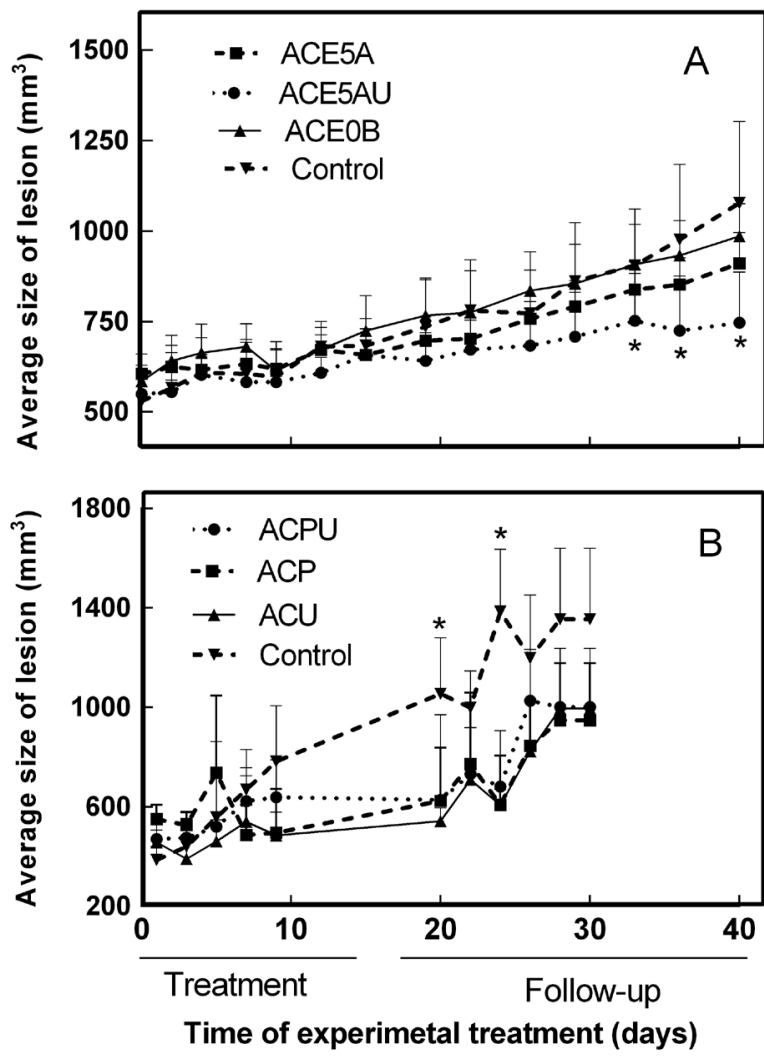

Figure 1. Effect of topical treatment on lesion growth using different formulas. Golden Hamsters (Mesocricetus auratus) infected with Leishmania (Leishmania) amazonensis, during and after topical treatment with $50 \mathrm{mg}$ day ${ }^{-1}$ of $\mathrm{A}$ - hydrating creams; B - anhydrous creams. Control: animals inoculated but without topical treatment. The data represent the mean \pm SD from 6 hamster/group. ${ }^{*} p<0.05$ when compared with all groups. 
caused a swelling and redness of the injury. The statistical test shows a significant difference between the ACE5AU group and the control group after 20 days at the end of the topical treatment $(P=0.0282)$, and this was the difference in increase after 30 days $(P<0.0001)$. Animals treated with formulation ACE5A showed a difference in lesion size when compared with the control group on the $40^{\text {th }}$ day $(P=0.0164)$. Thus, the ACE5AU group showed a difference compared with the ACE5A group on the $40^{\text {th }}$ day of trial $(P=0.0158)$. Lesions of the hamsters snout that received a treatment of ACE0B (no pentamidine, only constituents of cream) showed no significant differences between the control group $(\mathrm{P}>0.05)$. The average size of the lesions remained stable in the ACE5AU group during treatment, with a small increase in size after treatment, unlike the other groups that showed an increase in the lesion area. The average size of lesions in the ACE5AU group showed a reduction of $27.37 \%$ when compared with the control group on $40^{\text {th }}$ day of trial.

Development of the lesions in the groups that received treatment with anhydrous creams (Figure 1-B) showed no statistically significant difference in the average volume of lesions during 10 days of topical treatment. However, the follow-up of the infection after treatment which was observed on the $20^{\text {th }}$ day of the trial revealed that the control group had a significant increase in lesions, while the other groups that received a topical treatment had a constant amount of lesions. Statistical analysis showed that the three treatment groups, ACP, ACPU and ACU differed significantly from the control group $(\mathrm{P}<0.05)$ from the $20^{\text {th }}$ day until the end of the observation. The ACP group appeared to have a smaller average size of lesions with the anhydrous treatments, which had a statistically significant difference of NC $(P=0.0056)$ on $30^{\text {th }}$ day of trial. However, no statistical difference appeared between groups treated with anhydrous formulations. The average size of lesions for the ACP treatment group demonstrated a reduction of $26.63 \%$ when compared with control group on the $30^{\text {th }}$ day of trial.

Histological analyses of the imprints undergoing treatment with hydrating creams also showed the presence of amastigotes, a form of L. amazonensis, in all treated animals (Figure 2A, B). Parasite burden in lesions of treatments ACE5A and ACE5AU demonstrated a significant decrease. Statistical differences were observed between the ACE5A and ACE5AU treatments when comparing the percentages of amastigotes to the control groups $(P<0.001)$ Thus, quantity of amastigotes in the ACE0B group and control groups, showed no statistical difference $(P=$ $0.3915)$. The average percentage of infected macrophages did not show a statistical difference in any treatment group. Analysis of the mean values of the parasite burden present in the samples of the anhydrous groups showed a statistical difference with the control group when the quantity of parasites in ACP TT $(P=$ $0.0327)$ and ACPU TT $(P=0.002)$ were compared. However,
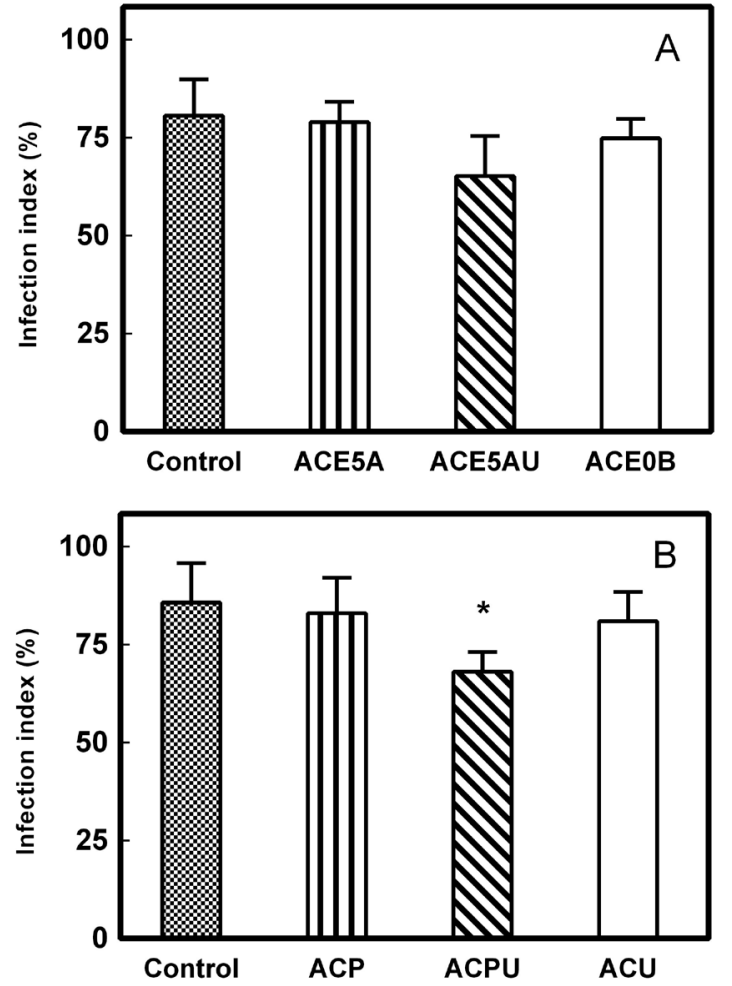

Figure 2. Inhibition of parasite growth by the topical treatment with formulas. The data represent the mean values of the infection index counted by imprinting lesions fragments stained with Giemsa and counted in $1000 \mathrm{X}$. A - hydrating creams; B - anhydrous creams. Control: animals inoculated but without topical treatment. The data represent the mean \pm SD from 6 hamster/group. ${ }^{*} p<$ 0.05 when compared with all groups.

the percentages of infected macrophages present in imprints showed a significant difference only between the ACPU group and the control group $(P=0.0309)$.

A difference in clinical morphology of nose was observed for the treatment with $\mathrm{ACE} 0 \mathrm{~B}$ which induced a lesion area of swelling. The swelling in the nose of the treated hamsters had a glossy appearance, which only occurred after applying the formulation. This fact was also observed in ACE5A group (Figure $3 \mathrm{D})$, but to a lesser extent. The group treated with ACE5AU also showed less swelling, and some of the animals started the process of scar and ulceration in the lesion area. In the control groups, the lesions remained without an increase in scabbing or scarring or sleek appearance of edema. The clinical appearance of lesions of the anhydrous treated groups showed no specific property to some group having the animals cells showing injury to production in virtually all groups.

Viability of the parasite in NNN after culturing fragments of lesions showed the presence of active parasites in all samples obtained from animals treated, with anhydrous and hydrating formulations, after eight days of incubation. This data was only 
qualitative as no measurement or quantification was observed, and to verify the ultrastructure of intracellular amastigotes in all treatments that the TEM was used. However, the cell morphology of parasites present in the lesions treated with ACP showed a suggestive alteration in the tissue visualized by microscopy. The results of the TEM demonstrated that the formation of parasitophorous vacuoles were containing amastigotes in all groups (Figure 4). However, there were morphological changes
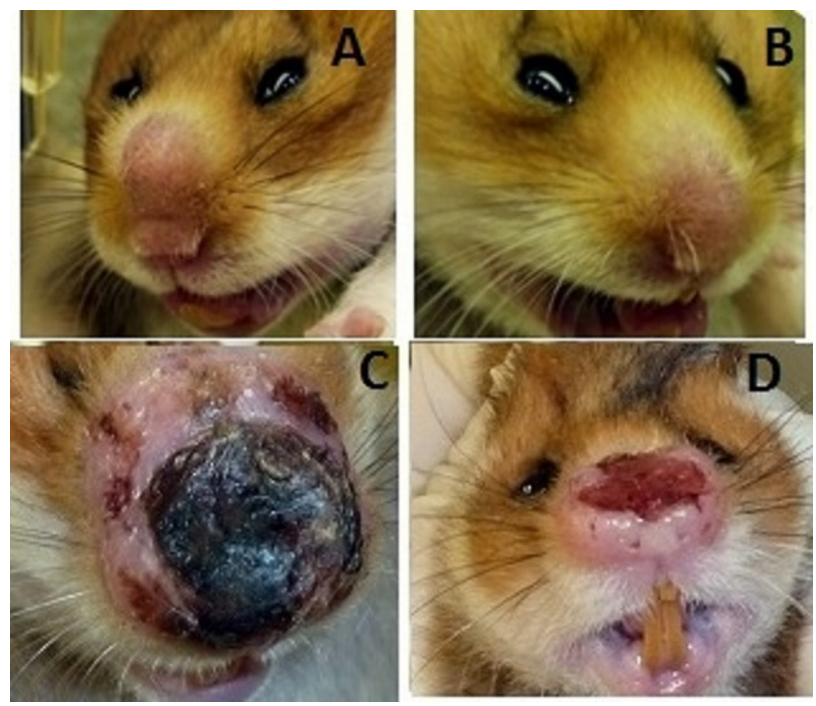

Figure 3. Evaluation of cutaneous leishmaniasis development in hamster treated with topical treatment. Clinical aspect of macroscopic lesions in Golden Hamster (Mesocricetus auratus) infected by Leishmania (Leishmania) amazonensis. A - Control Group: animals inoculated but without topical treatment, image of $3^{\text {rd }}$ day of treatment. B - ACE5AU Group: animals received $50 \mathrm{mg} \mathrm{day}^{-1}$ of formula with $10 \%$ pentamidine isethionate and $10 \%$ of usnic acid, image of third day of treatment. C - Control Group: animals inoculated but without topical treatment, image of $35^{\text {th }}$ day of treatment. D - ACE5AU Group: animals received $50 \mathrm{mg} \mathrm{day}^{-1}$ of formula with $10 \% \mathrm{PI}$ and $10 \%$ of usnic acid, image of $35^{\text {rd }}$ day of treatment. This figure is in color in the electronic version.

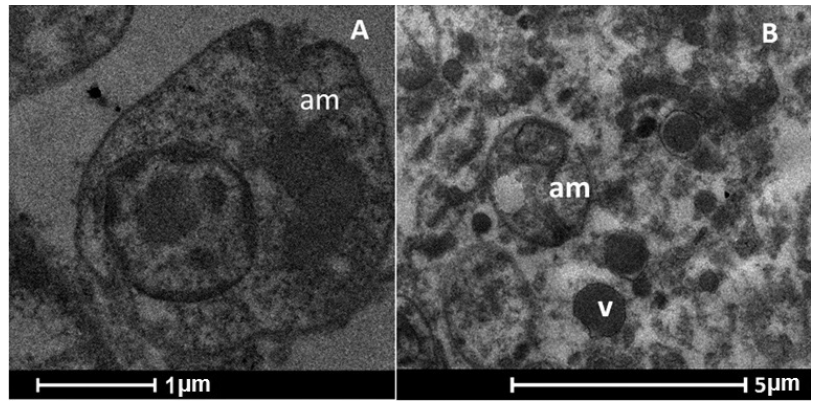

Figure 4. Photomicrography (TEM) of cutaneous lesion of snout tissue from hamster (Mesocricetus auratus) infected with Leishmania (Leishmania) amazonensis A - amastigote form (am) in host tissue of untreated hamster. $B$ - Tissue of a hamster treated with topical formulations containing Pentamidine (ACP), presence of (am) amastigotes forms in vacuoles and cellular vesicles (V). such as cytoplasmic vacuoles and vesicles in groups treated with cream containing pentamidine, as in the $\mathrm{ACP}$ group.

\section{DISCUSSION}

Although the parenteral treatment with PI is reported as the second choice for the treatment of leishmaniasis (Berman 2005; Minodier and Parola 2007; Mitropoulos et al. 2010), the PI has the advantage of a short time span and may be used in individuals intolerant to antimonial treatment (Mitropoulos et al 2010). No data for topical treatment applications has been reported to date with topical formulations containing PI.

A study in Colombia showed a $96 \%$ cure of CL in 51 patients who received a total of $4 \mathrm{PI}$ injections of $3 \mathrm{mg} \mathrm{kg}^{-1} \mathrm{day}^{-1}$ (Mitropoulos et al. 2010) and a 71\% cure was observed in 79 patients in Brazil that received 3 injections of $4 \mathrm{mg} \mathrm{kg}^{-1} \mathrm{day}^{-1}$ (Paula et al. 2003). Some authors recommend a single dose of $7 \mathrm{mg} \mathrm{kg}^{-1}$ (Oliveira et al. 2011). Formulations in this study were prepared with a concentration of $10 \%$ commercial PI, which represents a dose of $20 \mathrm{mg} \mathrm{kg}^{-1} \mathrm{day}^{-1}$. The hamsters each weighed approximately $200 \mathrm{~g}$. However, it was possible to observe the effects in the period after treatment, and longterm effects were demonstrated in treatment groups with creams containing PI, as the control of the lesions developed.

Biochemical studies with PI in promastigote of $L$. amazonensis and $L$. donovani reported that this drug gets accumulated inside the mitochondria and enhances efficacy of mitochondrial respiratory chain complex II inhibitors suggesting the leishmanicidal activities due to decreased mitochondrial membrane potential (Singh et al. 2012). However, there were other effects such as the inhibition of the use of S-adenosyl-L methionine and prevention of the synthesis of important molecules for maintaining the life of the parasite (Basselin et al. 1997; Silva-Lopez 2010) which may explain cell changes observed by TEM in the treatment with topical formulation containing pentamidine, as in ACP group. After analyzing the results of the parasite morphology post the treatment, there was the possibility that there was penetration of the drug across the epithelial tissues, and thus there was the possible preventing of the inflammatory response and parasite multiplication that occurs in the benign forms of CL in the animals submitted to anhydrous creams, particularly containing PI.

Results of the topical treatment with the diamidine based drug Trypan ${ }^{\circ}$ in BALB/c mice infected with $L$. donovani or L. major demonstrated that no effects were observed after 21 weeks of treatment when applications initiated after the lesions were established (Macharia et al. 2004). In this study, positive effects were observed in the topical treatment with PI, even when the application started after the appearance of lesions. Topical treatment of $\mathrm{CL}$ was associated with other drugs, such as the formulations containing $15 \%$ Paromomycin 
(El-On et al. 1993), Miltex (Schmidt-Ott et al. 1999), $25 \%$ podophyllin solution used topically (Sharquie et al. 2015) and tamoxifen (Eissa et al. 2011), that also used the size measurement methodology, clinical, and printing blade to monitor the effect of treatment. Also discussed was the possibility of using known drugs to develop new treatments that are also showing promising results.

The study showed positive results with 15\% Paromomycin causing parasite inhibition after 20 days of the application of the topical treatment, as do other studies in infection with other species of Leishmania (El-On et al. 1993). Our results are promising using topical treatments with formulations containing PI in lesions caused by L. amazonensis. This can be explained by the difference of conventional treatment and pharmacological kinetics of paromomycin and PI, when time of applications is short with PI. Larbi et al. (1995) found that the topical treatment was effective against $\mathrm{CL}$ in Saudi Arabia using creams containing 1\% clotrimazole and miconazole $2 \%$ in a randomized, double-blind clinical study. In this study, they observed that clotrimazole was the most efficient in reducing injuries, but it was still very limited for use in the treatment of leishmaniasis, with parasites still at the end of treatment. Similar results were observed when active promastigotes were found in all treatments after incubation of fragments of tissues in NNN.

Another study using the TT was with imidazoquinoline, a drug approved for the treatment of genital warts that showed activity against Leishmania by stimulating Nitrous Oxide production of infected macrophages and reducing the number of parasites. In the study of Miranda-Verastegui et al. (2005), which was conducted in the endemic regions of the Peruvian Andes and tropical forest, they included 40 patients which were infected by L. peruviana and L. braziliensis. However, the side effects that were reported in the group treated with imiquimod, were erythema, edema, itching, burning and pain (Almeida and Santos 2011). The parenteral administration of PI caused side effects such as musculoskeletal pains, anorexia, abdominal pains, nausea, headaches, asthenia and fatigues (Oliveira et al. 2011) could be reduced with a topical treatment application. Different creams were compared (anhydrous and hydrating) for their effectiveness on lesions with $L$. amazonensis. The ACE5AU treatments showed greater efficacy in the control of the developed lesion, but still was not able to inhibit parasites after treatment.

In the composition of the creams, Copaiba oil was incorporated, which has demonstrated activity against $L$. amazonensis by oral treatment (Santos et al. 2008), but the mechanism of topical application shows less efficacy. The leishmanicidal properties of usnic acid has also demonstrated some success by in vitro and in vivo experiments (Fournet et al. 1997), with a reduction in the weight of lesions and in parasite loads. However, Copaiba oil and usnic acid seem to have no effect in formulations without pentamidine in lesions caused by L. amazonensis, whereas group ACU (Andiroba, Copaiba and usnic acid) did not show a reduction in the size of lesions or parasite loads. Thus, multi-disciplinary efforts continue to be important in developing an effective topical treatment for treating CL. This could be done using new active compounds that can work concurrently with known drugs that have anti-leishmania action. In fact, the PI is completely absorbed after parenteral administration (Berman 2005), but the mechanism of action is by inhibiting different cellular processes, not yet fully elucidated.

Topical formulations containing PI have the potential to be a promising area of further studies for the treatment of CL. In treatment with PI there was observed in the animals treated, the presence of edema in the hydrating creams, but in treatment without PI, this effect may be attributed to formulation.

\section{CONCLUSIONS}

The treatment that demonstrated greater potential in the clinical aspects of the disease and efficiency with reduction of the total average size of the lesions was the group that received the ACE5AU cream. However, in all groups there was observed amastigotes without complete reduction of the parasites, although the morphological changes in the cells reduced the number of parasites when compared with the control groups of infected hamsters with $L$. amazonensis. This preliminary study demonstrated the potential of using topical treatments to reduce the number of parasites, and also could, with the association of others drugs, lead to a faster and more effective treatment of cutaneous leishmaniasis.

\section{ACKNOWLEDGMENTS}

The authors like to thanks to CNPq, FAPEAM and FP7PEOPLE-2011-IRSES- 295262: VAIKUTUS for financial support and Leonardo Brandão, from Central Biotery -INPA for assistance with animal care.

\section{REFERENCES}

Almeida, O. L. S. A.; Santos, J. B. 2011. Advances in the treatment of cutaneous leishmaniasis in the new world in the last ten years: a systematic literature review. Anais Brasileiros de Dermatologia, 86: 497-506.

Alvar, J.; Vélez, I.D.; Bern, C.; Herrero, M.; Desjeux, P.; Cano, J.; Jannin, J.; DenBoer, M.. 2012. Leishmaniasis worldwide and global estimates of its incidence.PLoS One, 9 e 35671

Alvar, J.; Croft, S.; Olliaro, P. 2006. Chemotherapy in the treatment and control of leishmaniasis. Advances in Parasitology, 61: $223-261$

Basselin, M.; Badet, M.A.; Lawrence, F.; Gero, M. 1997.Effects of pentamidine on polyamine level and biosynthesis in wild-type 
pentamidine treated and pentamidine-resistent Leishmania. Experimental Parasitology, 85: $274-82$

Bates, P. A. 2007.Transmission of Leishmania metacyclic promastigotes by phlebotomine sand flies. 2007. International Journal of Parasitology, 37: 1097-106.

Berman, J. 2005. Recent Developments in Leishmaniasis: Epidemiology, Diagnosis, and Treatment. Clinical Infectious Disease, 7: $33-38$.

Croft, S.L.; Seifert, K.; Yardley, V. 2006. Current scenario of drug development for leishmaniasis. Indian Journal of Medical Research, 123: 399-410.

Eissa, M.M.; Amer, E.I.; El Sawy, S.M.F. 2011.Leishmania major: Activity of tamoxifen against experimental cutaneous leishmaniasis. Experimental Parasitology, 128: 382-390.

El-On, J.;Livshin, R.; Even-Paz; Hamburguer, D. Weirauch, L. 1986. Topical Treatment of Cutaneous Leishmaniasis. Journal of Investigative Dermatology, 87: 284-288.

El-On, J.; Cawich, F; Evans, D.A.; Weirauch, L. 1993.Topical treatment of cutaneous leishmaniasis in Belize: in vitro and in vivo studies with Leishmania mexicana.International Journal of Parasitology, 23: 121-127.

Fournet, A.; Ferreira, M.E.; Arias, A. R.; Ortiz, S. T.;Inchausti, A.;Yaluff, G.;Quilhot, W.; Fernandez, E.; Hidalgo, M.E. 1997. Activity of compounds isolated from Chilean lichens against experimental cutaneous leishmaniasis. Comparative Biochemistry Physiology111:69-74.

Guizani, M.; Mukhtar, M.; Alvar, J.; Ben Abderrazak, S.; J. Shaw. 2011. Leishmaniasis. Encyclopedia of Environmental Health, 2: 453-480.

Larbi, E.B.; Al-Khawajaha, A.; Al-Gindan, Y.; Jain, S.; Abahusain, A.;Al-Zayer, A. 1995. A randomized double-blind clinical trial of topical clotrimazole versus miconazole for treatment of cutaneous leishmaniasis in the eastern province of Saudi Arabia. American Journal of Tropical Medicine and Hygiene, 52: 166-168.

Macharia, J.C.; Bourdichon, A. J.; Gicheru, M. M. 2004.Efficacy of trypan: a diminazene based drug as antileishmanial agent. Acta Tropica, 92:267-272.

Minodier, P. and Parola, P. 2007. Cutaneous leishmaniasis treatment. Travel Medicine and Infectious Disease, 5: 150-158.

Miranda-Verastegui C.; Llanos-Cuentas A.;Arevalo I.; Ward B.J.;Matlashewski G. 2005.Randomized, double-blind clinical trial of topical imiquimod 5\% with parenteral meglumine antimoniate in the treatment of cutaneous leishmaniasis in Peru. Clinical Infectious Disease, 40: 1395-403.

Mitropoulos, P.; Konidas, P.; Durkin-Konidas, M.2010. NewWorld cutaneous leishmaniasis: Updated review of current and future diagnosis and treatment. Journal of American Academy of Dermatology, 63: 309 - 322.

Murray, H.W.; Bermann, J.D.; Davies, C.R.; Saraiva, N.G. Advances in leishmaniasis.2005. Seminar, 77: 366-1561.
Oliveira, L. F.; Schubach, A. O.; Martins, M. M.; Passos, S. L.; Oliveira, R. V.; Marzochi, M. C.; Andrade, C. A. 2011. Systematic review of the adverse effects of cutaneous leishmaniasis treatment in the New World. Acta Tropica, 118: 87 - 96.

Paula, C. D. R.; Sampaio, J. H. D.; Cardoso, D. R.; Sampaio, R. N. R. 2003. Estudo comparativo da eficácia de isotionato de pentamidina administrada em três doses durante uma semana e de $\mathrm{N}$-metil-glucamina $20 \mathrm{mg} \mathrm{SbV/kg/} \mathrm{dia} \mathrm{durante} 20$ dias para o tratamento da forma cutânea da leishmaniose tegumentar americana. Revista da Sociedade Brasileira de Medicina Tropical, 36: $365-371$

Pinheiro, F. G.; Luz, L. S. B.; Franco, A. M. R.. 2008. Infecção natural por tripanosomatídeos (Kinetoplastida: Trypanosomatidae) em Lutzomyia umbratilis (Diptera: Psychodidae) em áreas de leishmaniose tegumentar americana no Amazonas, Brasil. Acta Amazônica,38: 165-172.

Rath, S.; Trivelin, L.A.; Imbrunito, T.R.; Tomazela, D.M.; Jesus, M.N. 2003. Antimoniais empregados no tratamento da Leishmaniose: estado da Arte. Quimica Nova, 26: 550-555.

Rossi-Bergmann, B.; Falcão, C. A. B.; Zanchetta, B.; Bentley, M. V. L. B.; Santana, M. H. A.2011. Performance of Elastic Liposomes for Topical Treatment of Cutaneous Leishmaniasis. Nanocosmetics and Nanomedicine. 9: 181-196.

Santos, A.O., Ueda-Nakamura T., Dias-Filho, B.P., Veiga-Junior V.F., Pinto A.C., Nakamura CV. 2008. Effect of Brazilian copaiba oils on Leishmania amazonensis. Journal of Ethnopharmacology, 120: 204-208.

Schmidt-Ott, R.; Klenner, T.;Overath, P.;Aebischer, T. 1999.Topical treatment with hexadecylphosphocholine (Miltex) efficiently reduces parasite burden in experimental cutaneous leishmaniasis. Transactions of the Royal Society of Tropical Medicine and Hygiene, 93: 85-90.

Sharquie, K. E.; Noaimi, A. A.; Al-Ghazzi, A. G. 2015.Treatment of cutaneous leishmaniasis by topical $25 \%$ podophyllin solution (single, blinded, therapeutic, controlled study). Journal of Dermatology \& Dermatologic Surgery, 19: 108-113.

Silva-López, R. E. 2010. Proteases de Leishmania: novos alvos para o desenvolvimento racional de fármacos. Química Nova, 33: $1541-1543$.

Singh, N.; Kumar1, M.; Singh, R. K. 2012. Leishmaniasis: Current status of available drugs and new potential drug targets Asian Pacific Journal of Tropical Medicine, 2012: 485-497.

Received: 08/05/2016

Accepted: 06/07/2016 
